\title{
Appraisal of Trends in Mathematics Education Curriculum: Gender and Indigenous Knowledge Perspectives
}

\author{
Lok Nath Bhattarai \\ lnbhattarai9@gmail.com \\ Lecturer \\ Central Department of Education, T.U., Kirtipur
}

\begin{abstract}
This paper is based on analysis of curriculum and experiences generated from mathematics teachers' educators and desk review of curriculum document. It also focuses the critical appraisal of the curriculum Trends in Mathematics Education on gender and indigenous knowledge perspectives This course is recently revised and approved by the Faculty of Education for Masters level students of Mathematics Education. This course has been designed and prepared to trace the trends of various aspects of teaching and learning mathematics education. It critically assessed the social, cultural, and inclusive educational issues and problems including gender and indigenous knowledge (IK) in teaching and learning mathematics practices at different levels from school to the university. The findings of the study shows that in the context of present curriculum Trends in Mathematics Education, there is little bit space for gender and IK but it is not sufficient. The opinion of teachers revels that some of the teachers integrated the issue of gender and IK on pedagogy, assessment and research. We can apply gender responsive pedagogy by inspiring students to make gender-reflections, generate greater equality in the classroom, and stimulate students to become gender-actors in society at large.
\end{abstract}

Keywords: Indigenous knowledge, Mathematics education, Curriculum trends, gender

\section{The Context}

The Curriculum is the best tool to transmit and transform the beliefs, values and culture of the society to every learner. Curriculum is directly related to pedagogy and assessment. The curriculum is best implemented through the textbooks, material and learning environment of the school, known as the hidden curriculum. Each and every society has its gender belief system and gender stereotypes i.e. the established images of what men and women are supposed to be like and reflected in the curriculum. When students enter the learning centers, the images of male and female portrayed in books, crystallize their concept about gender and consequently;their own self-image, their behavior, their aspirations and their expectations. If any change in the gender stereotypes is planned, serious and concerted efforts are required, firstly to analyze the learning material and secondly, to present those desired modified images. 
A progressive curriculum should be an agent of change in setting a direction for students but the present curricula and textbooks fall far short of such a role. The professional role models portraying women were too few and within a very narrow range of vocations and professions. Women were not even presented in the vocations primarily supported by them e.g. farming and head of institution. This situation reflects the social fact that women's work is not recognized and acknowledged as an economic activity.

The knowledge and skills of the students acquire from the universities are less practical and less relevant in their culture. In the context of mathematics on higher level, we focus on textbook based pedagogical practices assuming all learners have same ability to learn through the same activities. Our teaching strategies are one size fit for all and we as a content transmitter rather than reflective practitioner. The existing university level mathematics curricula are less compatible with the essence or notion of Ethno-mathematics in terms of incorporating the indigenous knowledge domains. In university level, we have different students from different cultures. In their houses they have different cultural practices.

\section{Indigenous Perspectives on Curriculum}

Indigenous perspectives on education have long history beside colonial models of education which is considered within the fields of multiculturalism, critical race theory, and progressive education. The concept of indigenous knowledge in education is looking for possibilities beyond the limits of liberal democratic schooling. The indigenous approach is attentive to relational validity as described previously, social justice education is concerned with catalytic validity (Fine, 2008). That is, what is valid in research is that which resonates with people's lives and informs their power to make change.

Indigenous knowledge is a body of knowledge that includes ideas, values, beliefs, and norms which are native and local (Akullo at el., 2007). It is based on experience of citizens and tested over centuries of use, adapted to the local culture and environment, embedded in community practices, institutions, relationships and rituals, and dynamic and changing (FAO, 2004). The students have reservoir of the indigenous knowledge and skills that acquired through day to day activities of living and transmitted on the generations' in meticulous socio-cultural setting. However, the practices of teaching and learning are disregarding this body of knowledge of lifeworlds of learners in learning process of universities. The Universities in Nepal are unable to foster these types of knowledge and knowing for promoting injustices by subjugating students' prior indigenous knowledge and skills. The indigenous knowledge of students acquired and accumulated in their own distinct cultural context often remain unused creating difficulties for conceptualizing newer modern ideas in the process of learning in higher level.

The Universities particularly in the third world countries like Nepal seem to be unwilling to promote indigenous knowledge and ways of knowing. The cosmic, practical, and everyday experiences of learners are not recognized our curriculum. The educational structures and teachers as agencies are not promoting contextualized teaching and learning activities and use imported pedagogical ideas and practices (Gay, 2002). The knowledge and skills acquire the students from their classroom are less practical and less relevant in their culture of living. The indigenous 
knowledge heritages are under defeat in the process of teaching and learning in structured classroom delivery. Students in our classroom came from multiple cultural backgrounds and hence they interpret the concepts of sustainable development and mathematics differently than standard views. On top of this, it is essential to identify the prior knowledge of students based on their culture for making meaningful learning. So, students bring a broad range of ideas, beliefs, values, and experiences to the classroom which forms a variety of viewpoints. Relating and reflecting practices on indigenous knowledge orient the students have to change the concepts privileging them to develop new concepts.

\section{Gender Perspectives on Curriculum}

Gender difference across discipline between women and men is still a relevant characteristic of education patterns(UNESCO, 2002). Women are entering the academy as consumers, rather than as producers of knowledge. The curriculum reform to mainstream gender issues and realities so that large cohorts of men and women students acquire a mandatory background on gender issues, as part of their learning experience. At the same time, it results in absence of female talent in mathematics, engineering, science and technology. The awareness and commitment for attaining gender equality is reflected in the present educational policies and plans. The concern for gender equality is generally visible among the policy implementers such as chairmen and members of textbooks boards. However, the concept of gender equality is perceived in a narrow sense by various participants and stakeholders.

According to Unterhulter et al. (2018), there are number of facets and complex perspectives related to gender equality in education. Therefore, the various set of relationships and the view of gender equality in education can be read in different ways, as gender issue is particularly a fluid term, is highly contextually located, and is thereby reflected in different formulations of policy and practice when enhancing gender equality (Unterhulter et al. 2018). Gender issue is never isolated from other factors that determine someone's position in the world, such as sexuality, race, class, ability, region of origin,citizenship status, life experiences,religion, and access to resources. Beyond studying gender as an identity category, the field is invested in illuminating the structures that naturalize, normalize, and discipline gender across historical and cultural contexts.

\section{Objectives}

Previous literature on integration of gender and indigenous knowledge dynamics on different contents is mostly concentrated in developed countries. As integration of the concept gender and indigenous knowledge is very rare in developing countries, the previous literature adds little to my understanding of gender and indigenous knowledge concept in content of Mathematics Education in Nepal. Therefore, this research, set to bridge this knowledge gap, examined perception, practice and beliefs about the integration of gender and indigenous knowledge perspectives on Trends in Mathematics Education curriculum in the Nepalese context. More specifically, it sought to fulfill the following objectives:

1. To explore embedded indigenous knowledge and gender issues in Trends in Mathematics Education. 
2. To find the integration of the concept gender and indigenous knowledge on the contents Trends in Mathematics Education.

3. To analyze the perception, practice and beliefs about the integration of gender and indigenous knowledge on Trends in Mathematics Education curriculum in the Nepali context.

\section{Review of Previous Study}

A Norwegian study conducted by UNESCO (1983) indicates that in the fourth to seventh grades, male and female stereotypes persisted in virtually all of the text books. Discriminatory attitudes towards girls and boys were manifested in the following ways: i)Boys frequently appeared with frequent illustrations. ii) The choice for males was unlimited and varied. iii) The examples and subject matter selected indicated a prejudice in favor of boys. iv) In science subjects like physics, chemistry and biology, it was found that there were far more pictures of males than of females for both the lower and upper secondary schools.

The World Federation of Teachers Union (1983) in a study of the portrayal of women and men in school textbooks and children's literature in France found that textbooks reflected the prevailing ideology and illustrated the general atmosphere of sexism at all levels of schooling. A survey conducted by Agency Famine Information (AFI-1982), of male and female characters in seventy-nine Arabic textbooks used in seven Arab states - Egypt, Lebanon,Qatar, Saudi Arabia,Tunisia, Democratic Yemen - showed the same stereotypes as modern countries. These textbooks describe women as dependent on men for economic welfare and status. They are depicted as weak, sensitive, dependent, self-sacrificing with no identity of their own as persons.

In the former Soviet Socialist Republic, a study conducted by UNESCO (1982) described the sexist stereotypes falling into three categories: i) Emphasize personality traits ascribed to one sex $(68 \%)$. According to such stereotype's men are efficient, courageous, reasonable, stubborn etc. Whereas women are typified by emotive traits, tenderness and solicitude. ii) Emphasize stereotype of family and occupational roles, traditionally associated with women, as housekeepers, nurses, teachers etc. while men are bread winners, managers of family etc. iii) Emphasize the difference in the social and political activities of men and women, women are passive men are authority figures.

Gay (2002) identified five elements of culturally responsive teaching as developing a knowledge base about cultural diversity, including ethnic and cultural diversity content in the curriculum, demonstrating caring and building learning communities, communicating with ethnically diverse students, and responding to ethnic diversity in the varieties of instruction So, Culturally responsive education can give those diverse students a third option: being academically successful while maintaining their cultural identities.

Similarly, Anderson and Haddad's (2005) survey in a comprehensive US public University showed that females experienced greater perceived deep learning, expressed their voice more strongly, had a greater sense of professor support, and had better control over their learning in an online environment in comparison with face-to-face courses. Caspi, Chajut, and Saporta (2008) came up with a similar finding and show that in an online environment; women participated 
significantly better than men did. However, they pointed out, despite some advantages offered by web-based instructional environment, especially for women, this environment is not attractive enough for either gender. In Yoo and Huang's (2013) study, females reported a significantly stronger intrinsic motivation for online learning than did the male participants. The study highlighted the need for more time for students without prior experience to get used to the online learning process so that they felt supported rather than overwhelmed by the new learning environments, expectations, and lifestyle. Moreover, research by Aesaert and van Braak (2015) revealed that the girls had better technical ICT skills and higher-order ICT competences than the boys. With regards to socioeconomic status, their findings also showed that the educational level of the mother was positively related to the technical ICT skills and higher-order ICT competences among female students. They further underscored the importance of screening and following up on online students' ICT competence as an adequate ICT background, which correlates with the completion rate of the students in online learning.

A recent study by Morante, Djenidi, Clark, and West (2017) in an Australian University also found that females were more engaged and achieved better than men did, though the overall participation in the web-based environment was meager in comparison to face-to-face classes.

In indigenous communities, knowledge is passed on through stories, oral histories, through rites of passage, ceremonies, and rituals that develop certain practical and vocational skills. Stories, however, are layered with learning; they tell a people who they are. For example, creation stories convey the philosophy and ontology of indigenous world views that are built upon cooperation, and connectivity and interdependence between all beings, markedly different from JudeoChristian, and other monotheistic religions, creation stories built upon hierarchy, binaries, and punishment. The tradition of oral storytelling constitutes an important dimension of indigenous literacy.

\section{Research Design}

This study adopted critical analysis of the Trends in Mathematics Education curriculum recently revised and approved by the Faculty of Education, TU. I adopted narrative inquiry research design. According to Webster and Mertov (2007, p.1),"narrative inquiry provides researchers with a rich framework through which they can investigate the ways humans experience the world depicted through their stories". Similarly, Khanal (2009) said, "Narrative inquiry is the process of gathering information for the purpose of research through story telling". Thus, I employed narrative inquiry to analyze the content Trends in Mathematics Education by gender and indigenous knowledge perspectives. The generalization was not the main aim of the study and it was confined to four mathematics teachers of Tribhuvan University.

\section{Informants}

The informants of the study include a total of four mathematics teachers ( 1 female, 3 male) who were teaching in four different constituent campuses of Tribhuvan University including two from Kathmandu valley and two from out of valley. They were selected following a purposive and convenience sampling technique. The informants had more than ten years of teaching experience and all voluntarily participated in this research (Cakmak, 2013). In detail, teachers between ten 
and twenty years of teaching experience were participated in the research. Teachers' subject area was mathematics education and taught the related content from same department since last ten years. To ensure anonymity, alpha-numeric identity (T1, T2, T3, \& T4) had been used for the participants involved in this study (Ambler, 2016).

\section{Data Collection}

I consulted curriculum document of Trends in Mathematics Education first. Then, the existing mathematics curriculum of Trends in Mathematics Education has been analyzed in order to examine indigenous knowledge and gender perspective of the students. To do this, an analysis table was constructed. After that, interview was conducted with teachers. The interview, being the most common and powerful research method, enables participants to speak for themselves. The semi-structured interview was used in order to elicit in depth data from the mathematics teachers on their perception, practice and beliefs about the integration of gender and indigenous knowledge perspectives on trends in mathematics education curriculum.

\section{Data Analysis}

The perception, practice and beliefs about the integration of gender and indigenous knowledge perspectives on Trends in Mathematics Education curriculum which was obtain from interview was interpret by using general inductive method as described by Thomas (2006). All interviews were first audio-recorded by the researcher by taking the informants' permission. Secondly, data was transcribed for analyzing process. Thirdly, content analysis was utilized based on the assigned codes, basic themes, organizing themes and global theme on the text. Finally, the global themes were defined in terms of the basic themes, organizing themes and codes given (as cited in Cakmak, 2013).Then, analyses were made in descriptive and critical form so as to achieve the objectives of this study with linkage to the literature. As the process of the interpretation and analysis, I triangulated the data and tried to establish the relation of the information from different informants.

\section{Results and Discussion}

To analyze teachers' perception, practice and beliefs about the integration of gender and indigenous knowledge perspectives on Trends in Mathematics Education curriculum, I present the views of teachers in different theme. In this section, the integration of gender and indigenous knowledge perspectives on the course of Trends in Mathematics Education is presented and discussed thematically. In the first part, I have addressed my research question "In what extend indigenous knowledge and gender are embedded in trends in mathematics education course"?For this I deeply studied curriculum of this subject. I have tried to discuss the analysis of curriculum whether it was incorporated indigenous knowledge and gender components in the curriculum and point out the indigenous knowledge and gender related themes.

This course has divided into six units and incorporated six general objectives. The six units have mathematics education at school and tertiary levels, trends in three basic areas of school mathematics, educational implications of applied mathematics, mathematics education conferences, and research in mathematics education. Out of six objectives the fifth objective is to acquaint the students with the critical appraisal to address different issues (Social and Cultural roles, Popularization, Gender differences, Ethno-mathematics, Inclusion) in mathematics education. 
From the analysis of curriculum, I found that some contents are related with indigenous knowledge such as in unit three there is one content, issue and problems of teaching learning in applied mathematics, in unit five, it incorporated gender difference in mathematics education, ethnomathematics, individual difference of students, special needs of students, issues and problems in student's evaluation system, and cultural role in teaching learning mathematics education. Similarly, in unit six, it mentioned the content areas of research in mathematics education. In this regard, the content of unit five focuses to give critical appraisal to address different issues (Gender differences, Ethno-mathematics, and Inclusion) in mathematics education. This unit also deals the mathematics education with respect to its social and cultural aspects. This means, the unit five provided the large space for indigenous knowledge and few spaces in gender perspective. It seems that there are many contents related to Indigenous Knowledge (IK) on course trends in mathematics education. Among six units, the four units gave the space of IK and only two units i.e. unit one and two were not address the concept. Likewise, very limited contents on unit four, five and six try to incorporated the gender issues in the curriculum of Trends in Mathematics Education. The mathematics curriculum of Nepal has been guided solely by a view of the nature of mathematics as a culture-free and pure body of knowledge (pure: symbolic, algorithmic, abstract) (Luitel \& Taylor, 2007) that is suited largely for academically bright students. To make mathematics students friendly, we should prepare the curriculum resource materials to countering such a hegemonic view by offering alternative knowledge systems residing in the cultural practices of people's lives.

\section{Practice of Integrating Gender and Indigenous Knowledge on Mathematics Teaching}

There are some good practices for integrating the concept of gender and indigenous knowledge in the context of mathematics teaching and learning. Central Department Education, Department of Mathematics Education and NORHED QUANTIC project organized different types of local level workshop and National level work shop, seminars and webinar that bringing together of gender and indigenous knowledge in Mathematics Education courses. So, initiation of Faculty of Education is encouraging for incorporating indigenous knowledge in Mathematics Education courses. In my concern about the practice of integrating gender and indigenous knowledge in teaching mathematics, one of my participants $\left(\mathrm{T}_{3}\right)$ says:

I try to my best to integrate the gender and IK issue in mathematics teaching by giving different examples related to our daily activities. I think the nature or the types of the knowledge of mathematics that we are going to incorporate is mostly depends on the society to which we are dealing with. In Nepal, different societies have different cultural norms, practices, necessity, and orientations. It leads the nature of local knowledge also differ onsociety wise. I always encouraged students to focus on those kinds of local ideas and practices related with basic counting system, measurement system, basic architectural skills, mathematics involved in the religious artifacts, ideas of calculating interest, age, and estimating different things on local community.

From the above view of my participant what I found that our university level mathematics courses need to revised and must incorporate the contents related to gender and indigenous knowledge so 
that it makes mathematics learning enjoyable and meaningful. However, it is a challenging task in the context of mathematics. Some of our mathematics teachers who taught in master's level were integrating the issue of gender and IK by presenting different examples related to students' daily life activities. Different people have different types of cultural norms, value system, and tradition in Nepalese context. Teacher must encourage students on focusing those types of local ideas and practices related to the daily life activities of the students in our mathematics classes. We can give different examples related to basic counting system, measurement system, basic architectural skills, local ideas of calculation like interest, age, local ideas relating to prediction of different ethnic groups so that they feel mathematics is for us.

In the same concern about the practice of integrating gender and indigenous knowledge in teaching mathematics another participant $\left(\mathrm{T}_{4}\right)$ expressed his view as:

We have several concepts of Gender and IK in our curriculum and we apply it in pedagogy, assessment and research in Department of Mathematics Education. We apply gender responsive pedagogy in our classroom. We have conducted different researches on Gender and IK. The literature say that mathematics is male dominant subject and low enrollment of girl's students in mathematics is the evidence for it. Due to time constraints, girl's students do not choose the mathematics subject. I think using active and participatory methodologies for identifying the day-to-day events that contribute to gender-based violence. It is not policy that is uncooperative; it is people who are uncooperative.

From the view of mathematics teacher, what I found that we teachers should apply equity pedagogy and storytelling, project work, and inclusive approaches while teaching mathematics. Basically, the concept of gender and IK is integrated in mathematics classes by applying it in pedagogy, assessment and research. Teachers encourage students to conduct research on Gender, IK, equity pedagogy, and social justice on master's level. Some of the University teachers apply gender responsive pedagogy by inspiring students to make gender-reflections, generate greater equality in the classroom, and stimulate students to become gender-actors in society at large. Teachers view also reveals that the enrollment of girls in mathematics is very low in comparison to boys and due to time constraints girls do not choose the subject. We can apply active and participatory methodology in class that helps to identify day to day events and helpful for reduce gender biased violence.

\section{Teachers Experiences on Integrating Gender and IK Issue in Pedagogical Practices}

We believe on teacher as a source of knowledge, text-books as center of knowledge, centrally developed curriculum, and university as center of learning. Using a gender conscious pedagogy, teachers can inspire students to make gender-reflections, generate greater equality in the classroom, and stimulate students to become gender actors in society at large. This type of pedagogy is possible in democratic classroom environment. Likewise,we need to integrating indigenous knowledge and ways of knowing with Western knowledge and knowing privilege students to develop new concepts in coherent manner, building synergy promotes inclusive practices and justice a hybrid or third space culture (Bhabha, 2006) of learning promotes meaningful learning. But in Nepal, educational institutions were opened and do not focused 
Appraisal of Trends in Mathematics Education Curriculum:... / 31

on knowledge production and use already established scientific knowledge in learning. In this regard, on my question"How did you experience to integrate the issues of gender and IK in your pedagogical practices"?Participant $\left(\mathrm{T}_{3}\right)$ answered as:

I face many challenges to integrate gender and IK in my teaching due to exam focused mind set of students. We feel comfortable when we express our understanding in familiar language and matched with the reality and context. Likewise, the students get more exposure when we give opportunities for them in learning and share something in their mother tongue. On top of this, they can link their understanding with various social and practical context of their living which leads them to see the gap between the knowledge they obtained and knowledge they required. But this type of activities rarely held in our class due to large class size and diverse nature of students in a single class.

From the view of my participant and me as researcher I found that if we give opportunity for our students to learn and share something in their own language, they get more exposure in learning mathematics. Likewise, students can link their understanding with different social activities of their surrounding that helps to find the gap between the knowledge they obtained and knowledge they required. The active participation of students becomes them empowering and critical thinker. The traditional curriculum framework, structured mind set of students, and exam centered teaching learning process are the major challenges to integrate gender and IK in pedagogical practices. The diverse nature of students in a single classroom and large class size also creates problem to integrate gender and IK issue in pedagogy and assessment.

Similarly, in my concern about the experience of participant to integrate the issues of gender and IK in pedagogical practices the participant $\left(\mathrm{T}_{2}\right)$ shares his experiences as:

As far I understood and experienced,we must give importance to the local knowledge for teaching because students feel ownership in their learning and they begin to share new knowledge with their friends and parents. This type of activities is helpful for the students to sharp their understanding. Most of the students in our class are already familiar with the ideas that we are going to incorporate in teaching so that they would have a certain schema regarding the use of that knowledge. In this situation the understanding of the learner becomes stronger if it matches with classroom activities.

From the above view of teacher, I came to know that the students get familiarized already from their home with the ideas that we are going to incorporate in teaching; they would have a certain schema regarding the use of those knowledge. The new knowledge became more permanent if it matched with already established knowledge. Teacher should give importance to the local knowledge on teaching helps to enhance the student's local culture that reflect our cultural values and change our western mind set and values. Likewise, the promotion of local knowledge and practices in classroom teaching helps students feel ownership in their learning so that it is helpful to sharp their understanding of mathematical concepts. 


\section{Attainment of Gender and Indigenous Knowledge in Students' Assessment}

The term assessment includes the full range of procedures to put on information about students' learning and formation of value judgment concerning their progress in relation to place academic standards. Assessment carry out learners' idea when they know what they are supposed to be learned, provides the opportunity to get regular feedback and know what is expected in order to gather educational standards. For attainment of gender issues and indigenous knowledge in students' assessment, in my question how did you experience regarding the assessment related with gender and IK? One of my study participants $\left(\mathrm{T}_{1}\right)$ says:

Only the paper pencil test is not sufficient to evaluate students' performance. We do not keep our focuses on the local ideas and practices while giving the assessment. Also, the examples and exercises provided in the curriculum materials are not good enough to link the mathematical content to the daily life activities of the students. Our institutions develop overloaded contents of mathematics in each level, which enforce teacher just to the bookish knowledge rather than connecting the content with the life skills of students. I apply many ways to evaluate the students' performance such as: quiz context, project work, group presentation and discussion on the subject matter and try to relate it with practices of local society.

In another concern about the experience of integrating gender and indigenous knowledge on students' assessment, another participant $\left(\mathrm{T}_{4}\right)$ expressed his views as:

First of all, we have to change our assessment system. Instead of using assessment of learning we use assessment for learning and ultimately, we use assessment as learning. Then we have been gradually integrating the elements of gender and IK in assessing the students learning. And we have been able to adapt the curriculum and pedagogies and assessment to some extent. We as the teachers are not in the same wave in this respect. But we do talk about it and sharing each other. Teacher mindset should be change. Instead of using single way of assessment we use multiple ways of assessment to link IK and gender so the assessment become culture and gender friendly.

From the above views of participants, the traditional paper pencil test is less effective in higher level mathematics. For making students assessment more effective we can apply multiple assessment system rather than paper pencil test. Some of our teachers apply comprehensive assessment system such as project work,quiz contest, group discussion, class presentation, communities visit, and field survey. Now, we must promote and apply comprehensive assessment system in each class. We claim that using multiple ways to access the students' performance is the best way. The similar views are expressed by Berger, Giroux, and Lariviere (2002). They claim many writers on learning assessment have confirmed that paper pencil tests are inadequate because they don't readily reveal the student's thinking. I am also on the favor of above views that, tests are the part of assessment; test is normally given at specified time intervals and test would not provide complete information about overall progress of a student. So, it would be better to apply student's real life and gender sensitive assessment to evaluate the student's overall performance. In my opinion we change our evaluation system. The assessment of the students should be applied as learning and assessment for learning rather than assessment of learning. Finally, we have been gradually integrating the elements of gender and IK and we have been 
able to adapt the curriculum and pedagogies and assessment to some extent. We teachers are not in the same wave in this respect. In this situation, teachers must change their mind set and aware to apply equity pedagogy in our class so that all students have equal opportunity to learn mathematics.

\section{Conclusion}

The analysis and interpretation of data conclude that the existing mathematics curriculum of Trends in Mathematics Education have the larger space of indigenous knowledge in comparison to the gender perspective even though it is not sufficient. The contents mentioned in the curriculum are appropriate to the level of students and sufficient for the development of necessary knowledge skills and attitudes to the Masters level students.

In the present situation the teaching- learning process is not still satisfactory in Masters Level. Our University level mathematics curriculum need to revise and must incorporate the contents related to gender and indigenous knowledge so that it makes mathematics learning enjoyable and meaningful. Some of our mathematics teachers who taught in master's level were integrating the issue of gender and IK by presenting different examples related to student's daily life activities. Teachers encourage students to conduct research on Gender, IK, equity pedagogy, and social justice on master's level. Some of the University teachers apply gender responsive pedagogy by inspiring students to make gender-reflections, generate greater equality in the classroom, and stimulate students to become gender-actors in society at large. Teacher should give importance to the local knowledge on teaching helps to enhance the student's local culture that reflect our cultural values and change our western mind set and values. Likewise, the promotion of local knowledge and practices in classroom teaching helps students feel ownership in their learning so that it is helpful to sharp their understanding of mathematical concepts.

The students' assessment system can make more effective than the present practices by applying comprehensive assessment system such as project work, quiz contest, group discussion, class presentation, communities visit, and field survey. This leads to evaluate the student's overall performance and better application of students' real life and gender sensitive assessment. The assessment of the students should be applied as learning and assessment for learning rather than assessment of learning. We have been gradually integrating the elements of gender and I.K. and we have been able to adapt the curriculum and pedagogies and assessment to some extent. We the teachers are not in the same wave in this respect. But we do talk about it and sharing each other.

\section{References}

Akullo, D., Kanzikwera, R., Birungi, P., Alum, W., Aliguma, L., \& Barwogeza, M. (2007). Indigenous knowledge in agriculture: A case study of the challenges in sharing knowledge of past generations in a globalized context in Uganda. Durban, South Africa: World Library and Information Congress.

Ambler, T. B. (2016). The day-to-day work of primary school teachers: A source of professional learning. Professional Development in Education, 42(2), 276- 289. doi: http://dx.doi. org/10.1080/ 19415257.2014.998343

Anderson, D. M., \& Haddad, C. J. (2005). Gender, Voice, and Learning in Online Course Environments. JALN 9 (1): 3-14. 
Berger, M. J., Giroux, R. F., \& Lariville, M. B. (2002). Learning and assessment of mathematics among Ontario francophone students, in the early and formative years, Toronto: Ontario institute for studies in education. Retrieved from http://www.eqao. Com/ pdf /e/02/02po28e.

Bhabha, H. K. (2006). Cultural diversity and cultural differences. In B. Ashcroft, G. Griffiths, \& H. Tiffin (Eds.), The post-colonial studies reader (pp. 155 - 157). London and New York: Routledge.

Cakmak, M. (2013). Learning from teaching experiences: Novice Teachers' Thoughts.

Caspi, A., Chajut, E.\& Saporta, K. (2008). Participation in Class and in Online Discussions: Gender Differences. Computers and Education,50 (3): 718-724.

Creswell, J. W. (2014). Research design: Qualitative, quantitative, and mixed methods approaches (4th ed). Thousand Oaks: SAGE.

Creswell, J.W.(2018). Educational research: Planning, conducting, and evaluating quantitative and qualitative research ( $4^{\text {th }}$ ed). New Jersey: Pearson Education.

FAO (2004). Building on gender, agro-biodiversity and local knowledge. Retrieved from http:// www.fao.org/sd/LINKS/documents_download/FS2Whatislocal\%20knowledge.pdf

Hacettepe Universitesi Journal of Education, 1, 55-67. Retrieved from:http://www.efdergi. hacettepe.edu.tr/yonetim/icerik/makaleler/279-published.pdf.

Gay, G. (2002). Culturally responsive teaching: Theory, research, and practice. New York.

Khanal, P. (2009). Educational research. Kathmandu: Sunlight Publication.

Luitel, B.C. \& Taylor, P.C. (2008). Globalization, ecological consciousness and curriculum as montage: A vision for culturally contextualized mathematics education. Paper presented at the annual conference of the Southern African Association for Research in Mathematics, Science and Technology Education(SAARMSTE): Maseru, Lesotho.

Taylor, P.C. \& Luitel, B.C. (2007). Fostering Socially Responsible mathematics education in rural Nepal. Paper presented at the annual conference of the Australian Association for Research in Education(AARE): Fremantle, Western Australia

Thomas, D. R. (2006). A general inductive approach for analyzing qualitative evaluation data. American Journal of Evaluation, 27( 2), 237-246. DOI: 10.1177/1098214005283748.

UNESCO (2002). Guidelines for Preparing Gender Responsive EFA Plans. Bangkok: UNESCO, Asia and Pacific regional Bureau for Education.

Unterhulter, A., North, A. \& Ward, O. (2018). Accountability for gender equality. Background paper prepared for the 2018 Global Education Monitoring Report. Gender Review. UNESCO. Accessed: August 4, 2020. https://www.gcedclearinghouse.org/sites/default/ files/resources/180145eng.pdf.

Webster, L. \& Mertov, P. (2007). Using narrative inquiry as a research method an introduction to using critical event narrative analysis in research on learning and teaching. Milton Park, Abingdon: Routledge.

Yoo, S. J., \& Huang, W. D. (2013). Engaging Online Adult Learners in Higher Education: Motivational Factors Impacted by Gender, Age, and Prior Experiences. The Journal of Continuing Higher Education 61 (3): 151-164. 